\title{
The Optical Properties of Gold
}

\section{A REVIEW OF THEIR TECHNICAL UTILISATION}

\section{Otto Loebich}

\author{
The characteristic optical properties of gold, combined with its \\ complete resistance to attack in any surroundings and its ability to \\ be applied as very thin films, have led to a number of interesting and \\ diverse applications in industry. The author, formerly Research \\ Manager to the Metals Department of DEGUSSA, reviews these \\ uses and the special properties upon which they are based.
}

There are several technical applications of gold where its optical properties are of prime importance and can contribute to the solution of various problems. These include:

The highly reflecting surfaces of satellites and space vehicles, of instruments on space capsules, and of space suits.

Reflectors with glass or metal backing in heating or cryogenic temperature engineering.

Plate glass windows in the motor-car and building industries for up to 50 per cent light transmission within certain frequency ranges and maximum reflection in other ranges.

Diffraction screens for optical instruments for certain wavelength ranges to act as focusing lenses, and also highly reflecting graduated scales.

Surface deposits on the solar energy distributors of solar cells to absorb radiated heat and to maintain the solar cells at optimum operating temperatures.

Radiation problems involving gold can best be discussed in terms of the actual applications.

There are cases where the Sun's radiated heat, i.e. the visible red rays as well as the infra-red (IR) rays, should be reflected to the maximum possible degree. Satellites are orbiting the Earth for periods of many months. They are exposed to solar radiation practically all the time. Their interior temperature, however, may only vary within a specified range. The recording and transmitting instruments would otherwise never be free from interference (2). The same applies to instruments on board lunar or planetary probes such as externally fitted control instruments (23).

Gold-plated spacesuits, too, are designed to protect their wearers from excessive solar radiation $(I, 10)$.
The solar energy striking any surface as electromagnetic radiation is about $1400 \mathrm{~W} / \mathrm{m}^{2}$, of which a maximum of $800 \mathrm{~W} / \mathrm{m}^{2}$ reaches the Earth's surface (in Germany on clear June days, about noon). Roughly half the Sun's light energy, if not more, is absorbed by the Earth's atmosphere. Approximately 99 per cent of the Sun's radiation is in the form of light at wavelengths between 200 and $4000 \mathrm{~nm}^{\star}$, with a maximum energy at $1500 \mathrm{~nm}$. Only at the ultra-violet (UV) end of the spectrum in the region between 200 and $300 \mathrm{~nm}$ is it almost totally absorbed. If space vehicles were not protected against the Sun's rays the interior temperature would be unbearable. The radiation range discussed in this paper is identified in technical literature partly by its wavelength and partly by its frequency or its electron energy. For ease of comparison the table shows a few related values of light wavelengths $\lambda$ in $\mathrm{nm}$, frequency $v$ in $\mathrm{sec}^{-1}$ and coordinated electron energy $\mathrm{E}$ in $\mathrm{eV}$. The range of visible light rays lies between approximately 380 and $810 \mathrm{~nm}$. $\lambda=500 \mathrm{~nm}$ corresponds to bluegreen, $\lambda=585 \mathrm{~nm}$ to the colour of a sodium flame and $\lambda=650 \mathrm{~nm}$ to orange-red.

For heating purposes the costly radiated heat is concentrated to the greatest possible extent. Domestic cookers, for instance, are fitted with high-speed heaters emitting infra-red rays between 750 and 3000 $\mathrm{nm}$. They are located at the focus of a gold-coated parabolic metal reflector (thickness of gold deposit approximately $200 \mathrm{~nm}$ ). An insulating oxide interlayer prevents the gold from diffusing into the refiector surface (29). Another system employing waves between 5000 and $15000 \mathrm{~nm}$ is used to accelerate the drying of paper after printing (29). Tugwell (23) discusses a hemispherical Westinghouse annealing dome, where the moulded steel dome of a space capsule is heated to $650^{\circ} \mathrm{C}$ and fitted over a

\footnotetext{
$\star_{1} \mathrm{~nm}$ (nanometre) $=10^{-9} \mathrm{~m}=10^{-6} \mathrm{~mm}=10^{-3}$ micron

$=10$ Angström.
} 


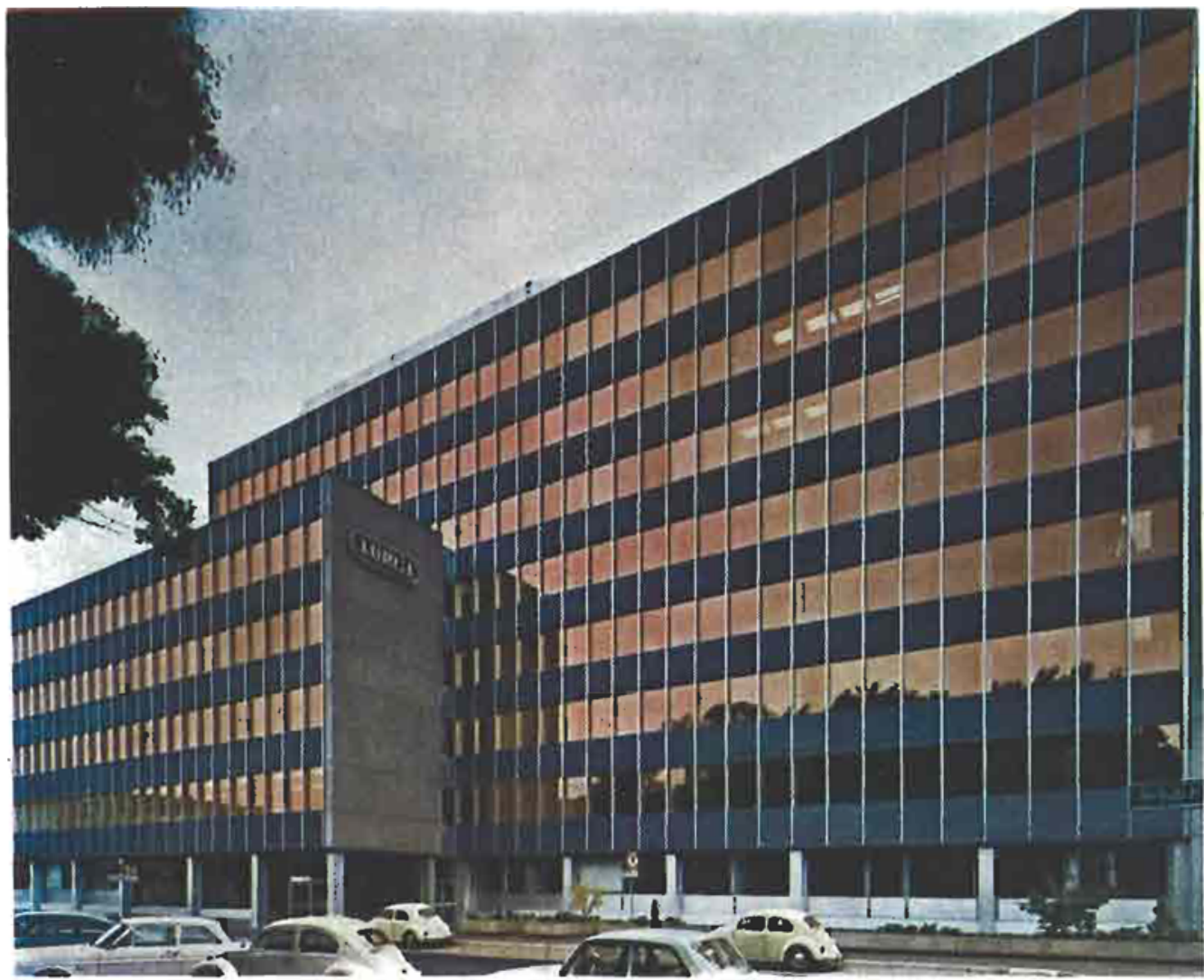

Thin gold films applied to plate glass windows give adequate transmission of light combined with good reflectivity in the infra-red range, so avoiding uncomfortable overheating of the building during hot weather. The Lurgi headquarters in Frankfurt is one of many office blocks and similar buildings fitted with such gold-coated windows made by Flaehglas A.G. Delog-Detag of Fürth, West Germany

former without using an excessive amount of power. The radiation from the heating bars is reflected by the gold-coated interior walls and is focused on to the steel dome. This is shown in the illustration on page 9 .

An electric motor situated close to equipment operating at temperatures of about $600^{\circ} \mathrm{C}$ was protected against radiated heat by a gold-plated capsule. The $250 \mathrm{~nm}$ thick gold deposit on the outside of the capsule was so efficient that the temperature of the motor could be kept at about $150^{\circ} \mathrm{C}$ instead of $400^{\circ} \mathrm{C}$.

Basically, gold deposits on the interior surfaces of Dewar vessels fulfil the same function in cryogenic temperature engineering (3).
Large plate glass windows in office buildings, front and rear windscreens of motor vehicles, and protective spectacles in iron foundries, steelworks, etc., are designed to transmit a portion of the visible rays and to screen off those other frequencies such as IR, which generate heat. This can be achieved by applying very thin gold films. Vacuum-deposited gold films up to $20 \mathrm{~nm}$ thick display good reflectivity in the IR range combined with adequate light transmission. They appear golden brown under reflected light and are blue-green in transmitted light $(6$, 24, 26).

A gold film $11 \mathrm{~nm}$ in thickness, vacuum-deposited on a glass surface pretreated with bismuth oxide, is

Some Corresponding Values of Wavelength $\lambda$ in nm, of Frequency $v$ in $\sec ^{-1}$ and of Electron Energy $\mathrm{E}$ in $\mathrm{eV}$

\begin{tabular}{|c|c|c|c|c|c|c|c|c|c|c|}
\hline$\frac{\text { Range }}{\lambda(\mathrm{nm})}$ & 100 & 220 & 300 & 380 & 500 & 700 & 810 & 1000 & 2500 & 10000 \\
\hline$v\left(\sec ^{-1}\right)$ & $3 \times 10^{15}$ & $\begin{array}{r}1.4 \\
\times 10^{15}\end{array}$ & $1 \times 10^{15}$ & $\begin{array}{c}7.9 \\
\times 1014\end{array}$ & $6 \times 10^{14}$ & $\begin{array}{c}4.3 \\
\times 10^{4}\end{array}$ & $\begin{array}{r}3.7 \\
\times 10^{14}\end{array}$ & $3 \times 10^{14}$ & $\begin{array}{c}1.2 \\
\times 10^{14}\end{array}$ & $3 \times 10^{13}$ \\
\hline
\end{tabular}


so even and uniform that it is capable of being electrically heated. It heats the windscreen and so prevents condensation in moist climates (24). A typical example of such an electrically heated windscreen is shown in the illustration on page 10 .

A patented heat-insulating screen (28) has also been described, coated with a gold alloy film composed of 90 per cent gold, 8 per cent nickel and 2 per cent chromium.

For very short wavelengths (UV and X-rays), a modified line grating or so-called zone plate is used in place of an optical lens to produce a real image. A sheet of beryllium or plastic material carries a series of concentric rings consisting of a radiation-absorbing metal such as gold, separated by concentric noncoated spaces; any radiation penetrating the backing material is deflected at each boundary between the gold and the interspace. The width of the metallised rings and uncoated spaces diminishes towards the periphery. Parallel light rays of a particular frequency range are deflected to a focus at a point on the axis. The width of the rings and spaces is adapted to the frequency range and may vary between 10 micron and 0.2 micron (27).

The legibility of a scale consisting of lightabsorbing graduations and light-reflecting intervals depends on the reflectivity of the backing material and of the metallising agent. For photoelectric infra-red scanning the ideal scale is composed of lightabsorbing black lines on a steel backing and of goldcoated spaces offering almost total reflection of the infra-red light (27).

A fired metallic film composed of 89.5 weight per cent gold and 10.5 per cent oxides $\left(\mathrm{BaO}, \mathrm{Bi}_{2} \mathrm{O}_{3}\right.$, $\mathrm{Cr}_{2} \mathrm{O}_{3}, \mathrm{SiO}_{2}$ ) will absorb a high percentage of incident light in the region $\lambda>700 \mathrm{~nm}$, in contrast to fine gold, which reflects more than 95 per cent of the radiation in the same frequency range. The energy absorbed is converted into heat. In this way the gold-coated parts of a solar cell in outer space are heated to a temperature above the surrounding temperature. A delicate adjustment between absorption capacity and surface reflectivity ensures that the solar cell is maintained within the temperature range calculated to give optimum performance (23).

\section{The Special Advantages of Gold}

At first sight it may be thought surprising that gold was selected to solve the above problems as it is neither a conventional nor a cheap material. But the tasks with which science was confronted could evidently not be solved by any other means. This is primarily due to certain optical properties of gold, more especially to its absorption and reflection behaviour in terms of the frequency of incident light. Two further considerations may have been decisive.
First, it undergoes no chemical change either under terrestrial or extra-terrestrial conditions, gold being the noblest of all metals known to industry; secondly, there is no difficulty in producing very thin films of gold of adequately uniform thickness and density. This may be achieved either by industrial processes on a mass production scale or by individual metallising processes.

\section{Physical Characteristics}

The terms and symbols used in discussing the optical properties of gold are briefly defined below:

The reaction of a medium to light or to electromagnetic radiation is determined by the refractive index $\mathrm{n}$ and by the absorption coefficient $\mathrm{k}$.

$$
\mathrm{n}=\frac{\mathrm{c}_{1}}{\mathrm{c}_{2}}=\frac{\sin \alpha}{\sin \beta}
$$

where $c_{1}$ and $c_{2}$ represent the speeds of light in mediums 1 and 2 . $\alpha$ and $\beta$ are the angles of incidence and of reflection. Furthermore

$\mathrm{k}=\mathrm{n} \times \quad \ldots \quad \ldots \quad \ldots \quad \ldots \quad \ldots$

where $x$ is the absorption index in the equation

$$
\mathrm{E}(\lambda)=\mathrm{E}_{0}(\lambda) \exp \frac{-4 \pi \mathrm{n} x \mathrm{~s}}{\lambda} \quad \ldots \quad \ldots
$$

Equation (3) represents the fall-off in energy occurring after a monochromatic $(\lambda)$ beam of energy $E$ has passed through a layer of the medium. $(n, x)$ having a thickness $s$.

When passing through a layer of thickness

$$
\mathrm{w}=\frac{\lambda}{4 \pi \mathrm{n} x} \quad \ldots \quad \ldots \quad \ldots
$$

the energy of the beam diminishes to $\frac{1}{\mathrm{e}} \mathrm{E}_{0}=0.368 \mathrm{E}_{0}$. The thickness $w$ is the penetration depth.

Using Maxwell's Theory the following values are obtained for an absorbing medium:

Supposing the complex dielectric constant

$$
\varepsilon^{\prime}=\varepsilon_{1}+\mathrm{i} \varepsilon_{2} \quad \ldots \quad \ldots \quad \ldots \quad \quad \ldots
$$

and the complex refractive index

$$
\mathbf{n}^{\prime}=\mathbf{n}+\mathbf{i k} \quad \ldots \quad \ldots \quad \quad \ldots \quad \ldots
$$

where

$$
\begin{array}{lllll}
\varepsilon^{\prime}=\mathrm{n}^{\prime 2} & \ldots & \ldots & \ldots & \ldots
\end{array}
$$

we find

$$
\varepsilon_{1}=\mathrm{n}^{2}-\mathrm{k}^{2} \quad \ldots \quad \ldots \quad \ldots \quad \quad \ldots
$$

as a value for dispersion and

$$
\begin{array}{llllll}
\varepsilon_{2}=2 \mathrm{nk} & \ldots & \ldots & \ldots & \ldots
\end{array}
$$

as a value for absorption.

A beam $E_{0}$ striking a plane surface of the medium $(n, x)$ at right angles is partly absorbed, partly reflected and partly transmitted if the layer is 


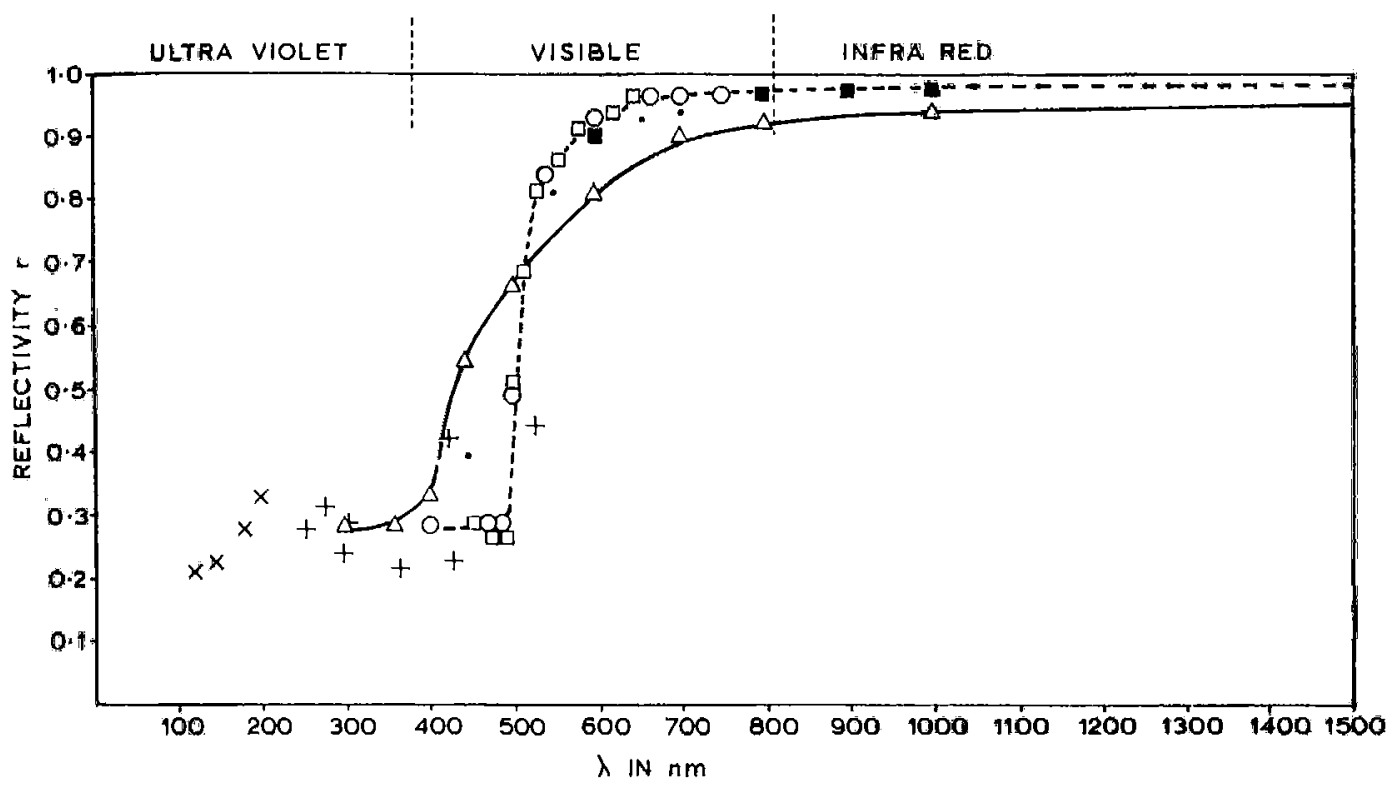

Fig. I Reflectivity $r$ of gold in terms of the wavelength $\lambda$ of light in $n$ m. Combined results of several studles.

$\begin{array}{llll}\text { D Dickson and Jones (3) } & + \text { Pfestorf (16) } & \circ \text { Knosp (7) } & \times \text { Robin (17) } \\ \square \text { Otter (13) } & \text { - Schulz (19) } & + \text { Philip (15) } & \Delta \text { Stabe (21) }\end{array}$

sufficiently thin. Where the coefficient of absorption is a, the reflectivity is $r$ and the coefficient of transmission is $d$, the following equation applies:

$$
\mathbf{a}+\mathbf{r}+\mathbf{d}=1
$$

$\mathrm{E}_{\mathrm{ref}}=\mathrm{r} . \mathrm{E}_{0}$ and $\mathrm{E}_{\mathrm{abs}}=\mathrm{a} . \mathrm{E}_{0}$, also $0<\mathrm{r}<\mathrm{I}$ and $0<\mathrm{a}<1$. Also

$$
\mathrm{r}=\frac{(\mathrm{n}-1)^{2}+\mathrm{k}^{2}}{(\mathrm{n}+1)^{2}+\mathrm{k}^{2}} \quad \ldots \quad \ldots \quad \ldots
$$

According to Kirchhoff, $a \equiv e$, i.e. the emissivity of a temperature radiator. Its radiated energy
$E$ is related to the radiation energy $E_{s}$ of a black radiator at the same temperature by

$$
\mathrm{E}=\mathrm{e}, \mathrm{E}_{\mathrm{s}}
$$

\section{Test Results on Opaque Gold Layers}

Figures 1 and 2 illustrate the combined findings of various authors on solid fine gold and vacuumdeposited films.

Figure 1 shows the reflectivity $r$ as a function of the wavelength $\lambda$. In the infra-red and long wave ranges

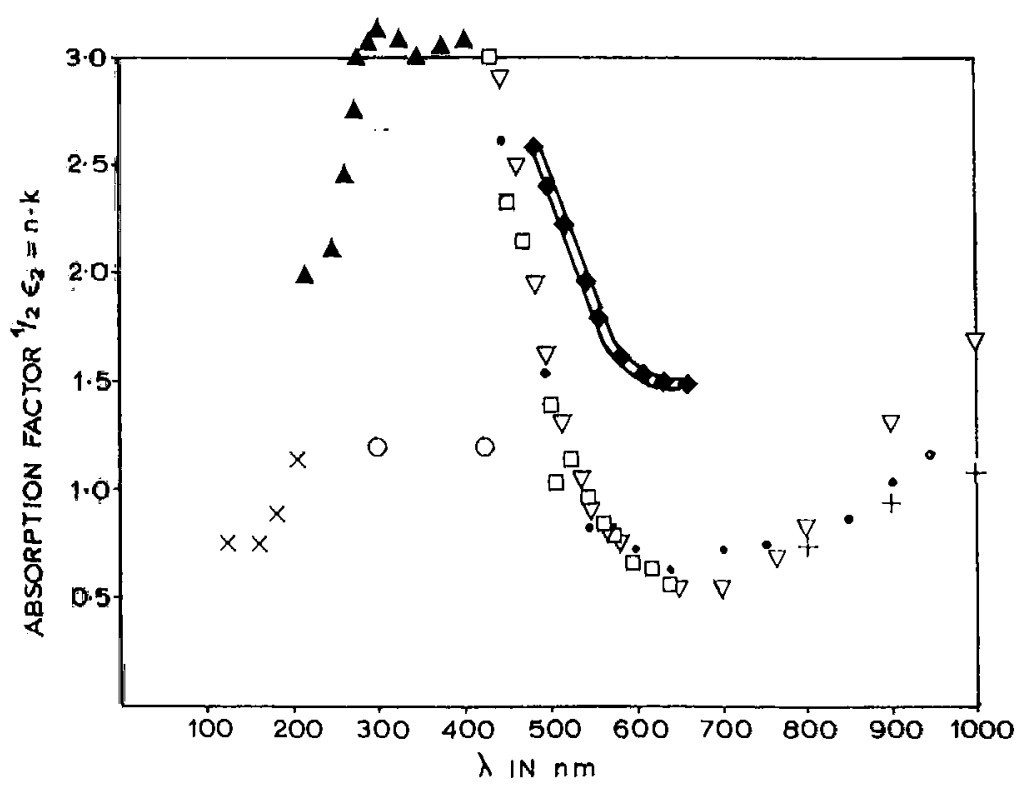

Fig, 2 Absorption factor $c_{2}=n k$ of gold in levms of the wavelength $\lambda$ of light in nm, Combined results of several studies

$\Delta \nabla$ Köster and + Kretzmann (9) Stahl (8) O Philip (16)

$\square$ Otter (13) - Behuk (19)

$\times$ Robin (17)

$\rtimes$ Otter, $920^{\circ} \mathrm{C}(13)$ 


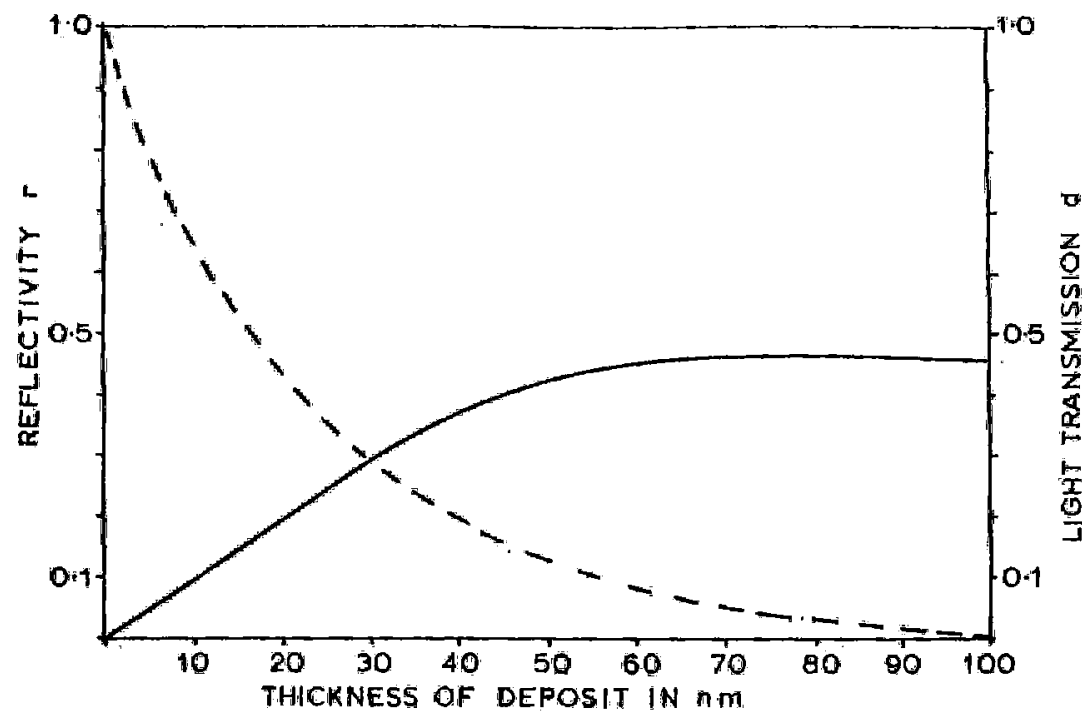

Fig. 3 Reflectivity y and light transmission $d$ of thin gold filme in terms of their thickness in nm tor light of wave. length $\lambda=492 \mathrm{~mm}$. of visible light gold reflects more than 95 per cent of incident light. According to Dickson and Jones (3) for vacuum-deposited gold of 99.999 per cent purity reflectivity values between $\lambda=2000 \mathrm{~nm}$ and $32000 \mathrm{~nm}$ of $r>0.99$ have been measured. Below $\lambda=650 \mathrm{~nm}$ $r$ falls off steeply with diminishing wavelength. According to recent tests $(7,13)$ this decrease is much steeper than was supposed previously $(15,21)$. The difference may possibly be due (7) to lattice imperfections and surface defects of the samples which it had been possible to avoid or to correct carefully on later occasions.

Figure 2 shows that at $\lambda=650 \mathrm{~nm}$ gold has a well-defined absorption limit. At longer wavelengths the standard absorption term of ${ }_{2}^{1} \varepsilon_{2}=n k$ increases only very slightly with the wavelength.

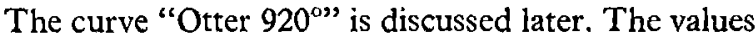
measured according to Philip (16) and Robin (17) for $\lambda \leqslant 430 \mathrm{~nm}$ do not accord well with the more recent findings of Knosp (7), Köster (8) and Otter (13). It may be assumed from the results of Knosp that the vacuum-deposited gold layers of Philip and Robin were not sufficiently free from defects. The results of Knosp, Köster, Otter, and Stahl (22) show excellent agreement, whereas those of Fragstein (4) and Nilsson (12) agree less well. In the violet and nearby ultra-violet regions of the spectrum the absorption of gold has maxima at $\lambda=400 \mathrm{~nm}$ and $320 \mathrm{~nm}$, respectively.

\section{Test Results on Semi-transparent Gold Deposits}

Gold deposits transmitting a noticeable amount of light are between 5 and $40 \mathrm{~nm}$ thick. According to equation (4) the penetration depth for $\lambda=1000 \mathrm{~nm}$ is about $13 \mathrm{~nm}$, whereas for $\lambda=500 \mathrm{~nm}$ it is about $70 \mathrm{~nm}$. Thin gold deposits could, therefore, be expected largely to reflect red light and IR while partially transmitting shorter wavelengths. At transmission factors of $d=0.5$ to 0.2 for $\lambda=700 \mathrm{~nm}$ the results of Kautz (6), Mayer (11), Pepperhoff (14), Schulze (20), and Wise (24), for instance, showed reflectivity $\mathrm{r}=0.9$, whereas for $\lambda=492 \mathrm{~nm}$ the value of $r$ was 0.1 to 0.3 . See also Fig. 3. Figure 4 shows the light transmission of a commercial product. The transmitted light of gold deposits $4 \mathrm{~nm}$ thick and over is of the same blue-green colour as that of beaten gold leaf (11). Thinner films between 1 and $4 \mathrm{~nm}$ thick give a grey, yellow-red or violet light,

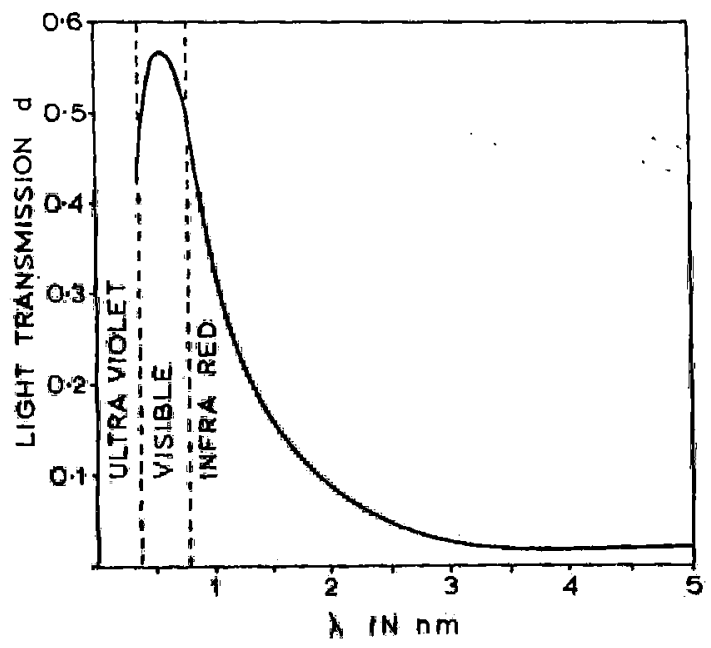

Fig. Light transmission d of vacuum deposited gold on commercial glass in the wavelength range from 0.4 to 5 pam $(14,26)$ 
according to the process used for deposition. As in the case of colloidal aqueous gold solutions, this is explained as being due to a colloid-like grain structure.

\section{Influence of Temperature}

Figures 2, 5 and 6 illustrate the absorption $\frac{1}{2} \varepsilon_{2}$, the reflectivity $r$ and the emissivity e of gold in terms of temperature.

Figure 2 shows a curve based on Otter's (13) measurements at $920^{\circ} \mathrm{C}$. It shows that between $\lambda=500 \mathrm{~nm}$ and $600 \mathrm{~nm}$ the quantity nk according to equation (8) increases at higher temperatures. The absorption edge of gold becomes less steep as a result.

According to Fig. 5 the reflection of longer wavelengths $\lambda \geqslant 500 \mathrm{~nm}$ decreases slightly at higher temperatures. This is understandable when remembering the detrimental effect of lattice defects on the reflectivity, as illustrated by Fig. 1 (7). After comparing two curves in the IR range drawn up by two workers for gold films deposited at $82 \mathrm{~K}$ and room temperature, respectively, Dickson (3) concludes that $r$ is affected significantly by the surface finish; the reflectivity $r$ is said to increase with mechanical polishing, high vacuum deposition, electroplating, and ultra-high vacuum deposition, in that order.

Short wavelength light with $\lambda<500 \mathrm{~nm}$ is reflected better by a hot gold surface than by a cold one. At $\lambda=500 \mathrm{~nm}$ the reflectivity remains unaffected by temperature. This finding is important for the theoretical interpretation of the optical properties of gold (the so-called X-point). Stahl et al. (22) place the $\mathrm{X}$-point of gold at $\lambda=475 \mathrm{~nm}$.

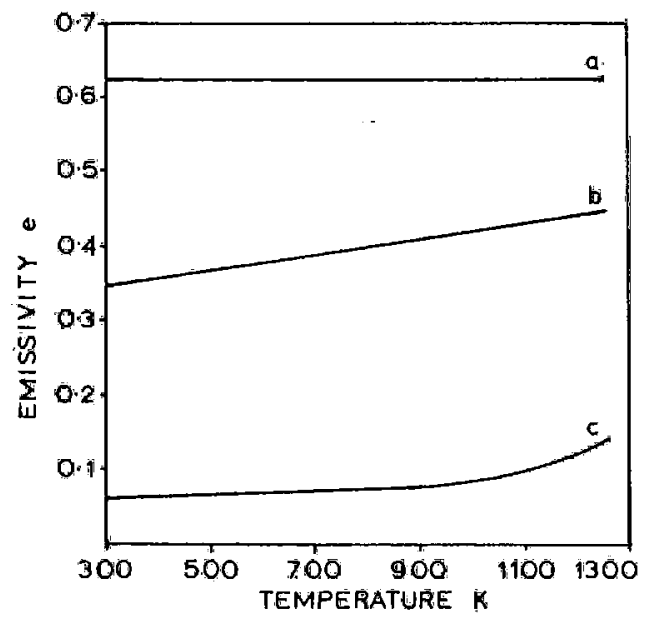

Fig. 6 Emissivity e of gold as a function of tempera: ture between 300 and $1280 \mathrm{~K}$, according to Worthing (25). a i $\lambda=460 \mathrm{hm}$, bi $\lambda=535 \mathrm{~nm}$, ci $\lambda=665 \mathrm{~nm}$

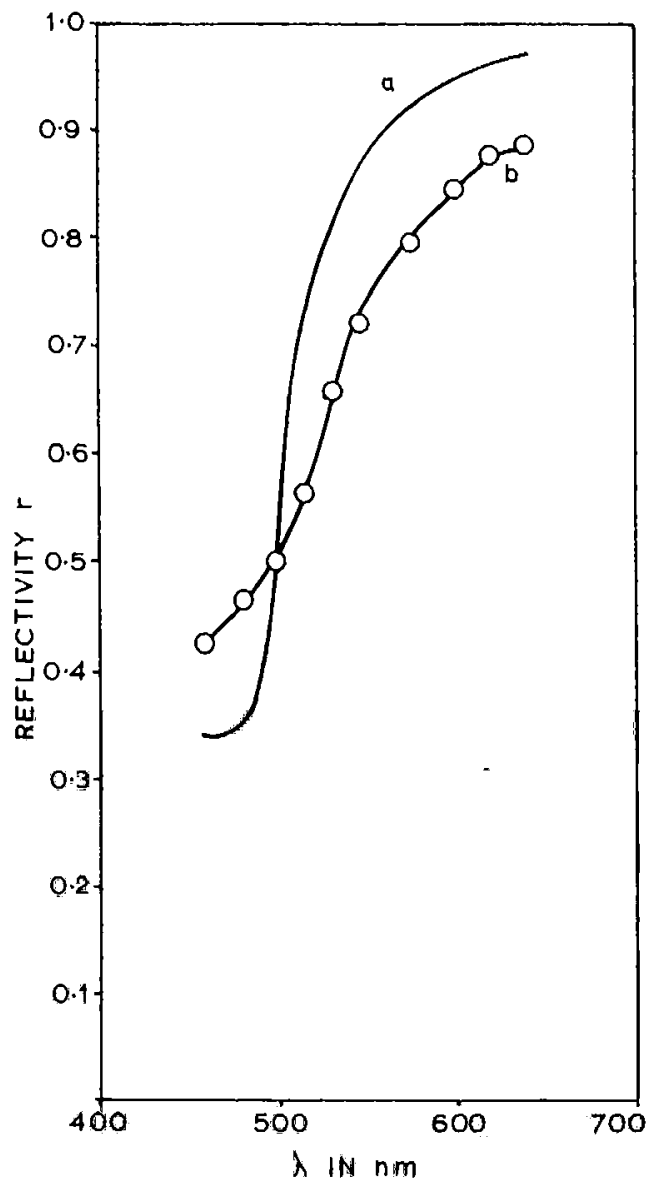

Fig. 5 Reflectivity $r$ of gold in terms of the wavelength $\lambda$ of light in $\mathrm{nm}$, at 10 and $920^{\circ} \mathrm{C}$ (13). a: $10^{\circ} \mathrm{C}$, b, $920^{\circ} \mathrm{C}$

Figure 6 demonstrates the effect of temperature on the emissivity e. According to equations (9) and (11), $\mathrm{e}=1-\mathrm{r}$. In the wavelength region around $500 \mathrm{~nm}$ e remains practically constant between 300 and $1300 \mathrm{~K}$. It is established that $\mathrm{e}$ increases with temperature at the long-wave end of visible light where $\lambda=535 \mathrm{~nm}$ to $665 \mathrm{~nm}$. It follows that reflectivity diminishes as shown by Fig. 5 .

\section{Influence of Alloying}

Generally speaking the colours of carat golds are different from (paler than) that of fine gold. The effect on the optical constants may be observed from Figs. 7 and 8, both based on the test results of Köster (8) and Pepperhoff (14) on the gold-silver system. Figure 7 shows the reflectivity of gold, silver and gold-silver alloys (the stated compositions presumably refer to atomic percentages). The radiation range examined is between $300 \mathrm{~nm}$ and $550 \mathrm{~nm}$. The curve for gold corresponds no more than loosely 


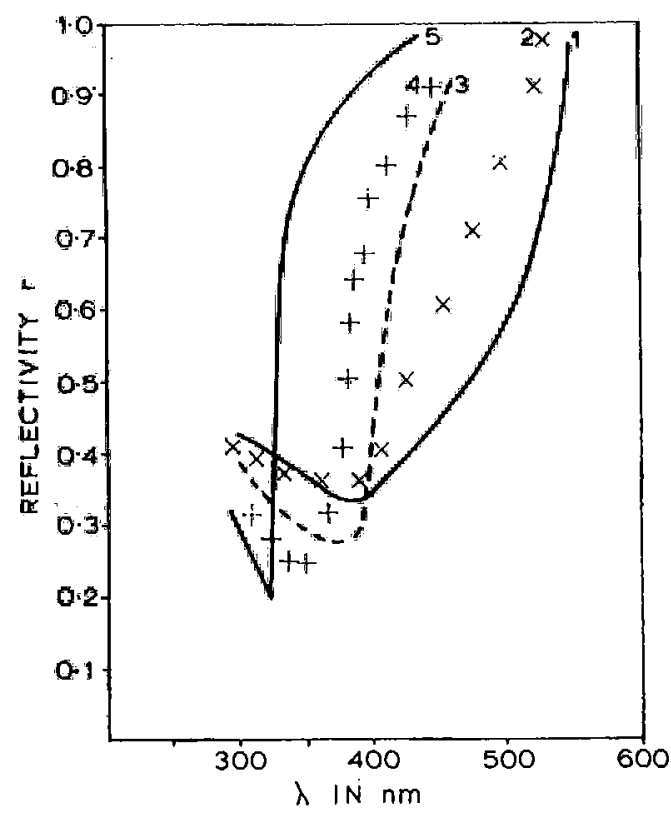

Fig. 7 Reflectivity of gold, silver and three goldsilver alloys in terms of the wavelength $\lambda$ of light in nm, according to Pepperhoff (14). Curve 1: $100 \%$ Au, curve $2: 85 \%$ Au-15\% Ag, eurve $3: 50 \%$ Au-50 $\%$ Ag, curve 4: $30 \%$ Au-70 $\%$ Ag, curve 5: $100 \%$ Ag

to that of Fig. 1 and the same may be said for the silver curve. Despite this limitation it is evident from Fig. 7 that with increasing silver contents the reflectivity curve shifts fairly steadily from the visible into the ultra-violet range. For alloys having a predominantly silver content the minimum of the reflection curve is likewise steadily shifted from the region around $\lambda=400 \mathrm{~nm}$ for gold to the region around $\lambda=325 \mathrm{~nm}$ for silver.

Figure 8 represents $\frac{1}{2} \varepsilon_{2}=$ nk, i.e. the standard absorption term of equation (8) for gold, silver and three gold-silver alloys in the range $\lambda=300 \mathrm{~nm}$ to $700 \mathrm{~nm}$. At around $550 \mathrm{~nm} \mathrm{nk}$ is substantially independent of composition. For each wavelength above $\lambda=550 \mathrm{~nm}$ the alloy containing 50 atomic per cent silver as a rule shows the highest absorption. In the short-wave region below $500 \mathrm{~nm}$ the absorption edge of gold slides steadily into the UV with increasing silver content; at the same time the absorption minimum is lowered.

Both figures are in reasonable agreement and represent a short survey on the effect of alloying on the optical properties of gold. Gold-copper alloys are discussed by Köster (8) and Stahl (22).

\section{Theoretical Approach}

The interpretation of the results discussed so far forms the subject of a number of papers. The optical constants of metals are closely related to their electrical properties and the state of the electrons in the metal lattice. A quantum mechanical evaluation of the results has been attempted more than once but a satisfactory quantitative interpretation is still awaited; the conclusions briefly cited below are all supported by evidence. A more detailed treatment may be found in papers by Freund (5), Knosp (7), Köster (8), Nilsson (12), Pepperhoff (14), and Stahl (22), and in the literature there quoted.

The absorption and reflection of electromagnetic radiation for gold at $\lambda \geqslant 10$ micron may be inter-

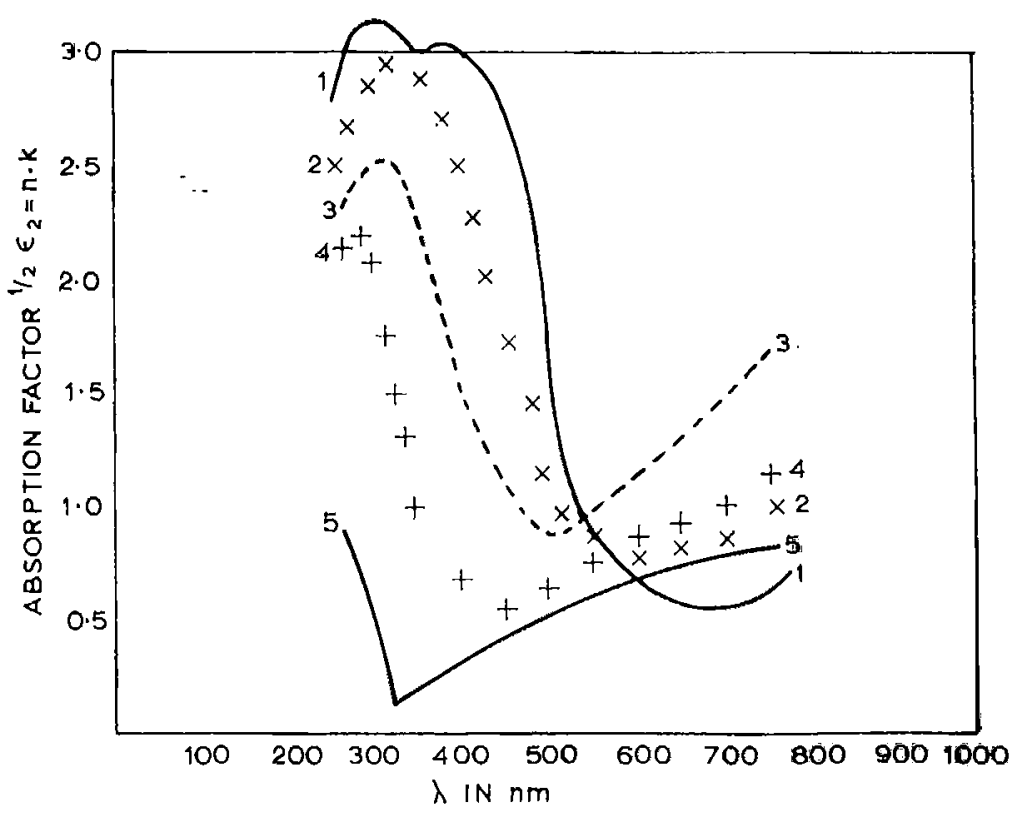

Fig. B Absorption factor $\frac{1}{2} \varepsilon_{g}=n k$ of gold, silver and three gold-silver alloys in terms of the wavelength 2 of light in IIm, according to Köster and Stahl (B). Curve 1: $100 \% \mathrm{Au}$ curve $Z, 80 \%$ Au.20\% Aig, curve 3 : $50 \%$ Au-50\% Ag, curve $4: 20 \%$ $\mathrm{An}-80 \% \mathrm{Ag}$, curve $5,100 \% \mathrm{Ag}$ 
In the final sizing of steel domes for rocket casings a heat-forming operation was devised by Westinghouse in whieh the casing was accurately expanded over a mandrel at $650^{\circ} \mathrm{C}$. Heating was from high temperature quartz lamps, with goldcoated reflectors to concentrate the heat on the mandrel and work-piece and at the same time to prevent heat losses to the wiring and the structure behind the reflectors

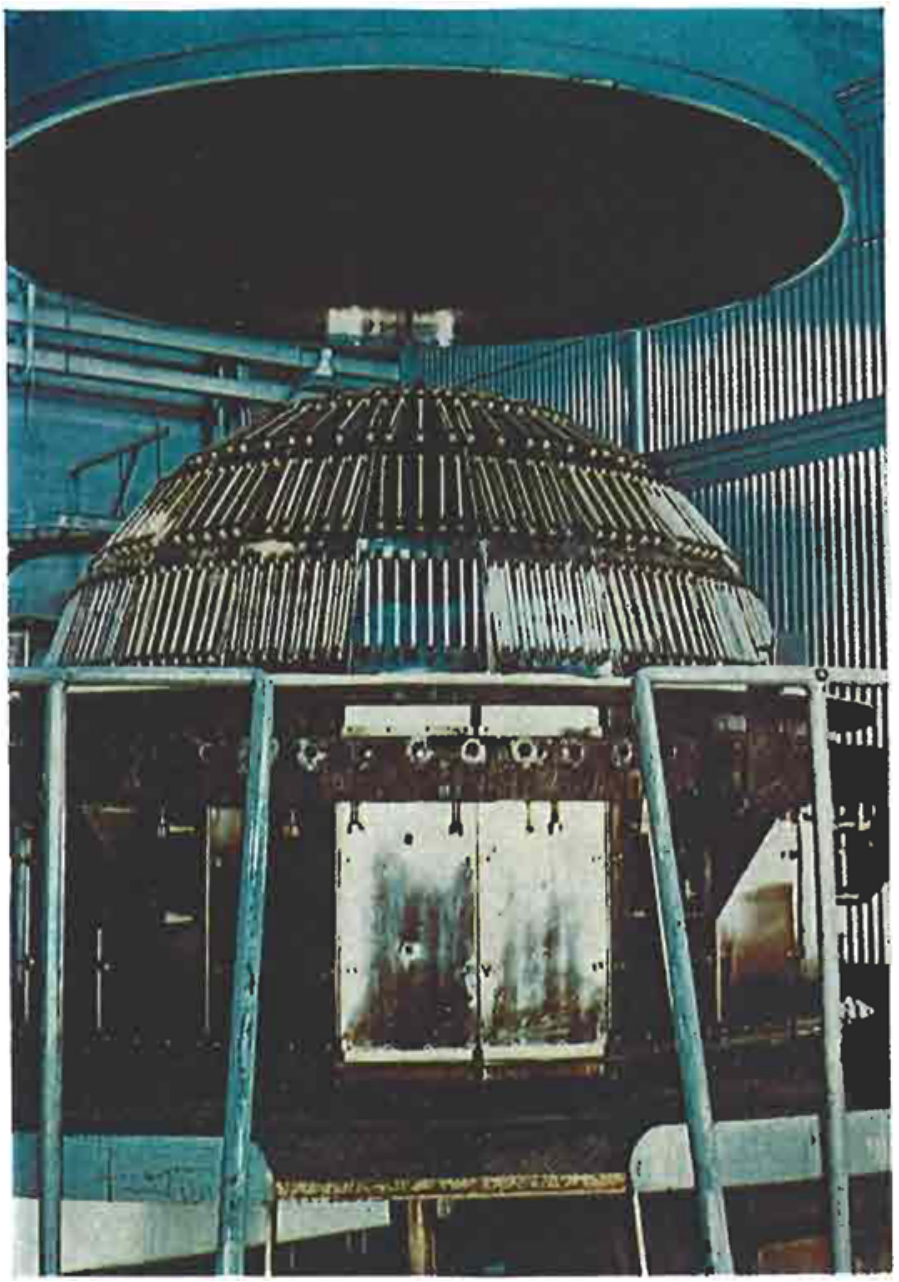

preted in the classic physical sense in terms of the Hagen-Rubens equation. According to Pepperhoff (14), the Drude theory of free electrons applies down to $\lambda \geqslant 700 \mathrm{~nm}$ but the theory fails to cover wavelength ranges subject to quantum absorption.

The point of departure for both definitions is the fact that at frequencies below $3 \times 10^{13} \mathrm{sec}^{-1}$ no measurable interaction occurs between the light quantum and the energy state of the fixed electrons. In this case the absorption of the metal is very small and light radiation is almost totally reflected. Shorter wavelengths, where frequencies are of the order of, say, $10^{15} \mathrm{sec}^{-1}(\lambda=300 \mathrm{~nm})$, belong to an energy range where quantum transition becomes possible and light absorption may take place. An evaluation of this quantum absorption or absorption by fixed electrons has been attempted by quantum mechanical considerations based on the band model.

Defects in the lattice, as well as the presence of alloying atoms, tend to aggravate light absorption by free electrons, i,e. at the long-wave end of the spectrum. Any rise of temperature will produce the same effect. The effect of short-range or long-range order on the optical properties of gold alloys is discussed in detail by Köster (8) and Stahl (21). The absorbed radiation energy is partially re-emitted (possibly involving changes in frequency) as soon as the excited electrons return to their original state. Part of the absorbed energy is converted into heat as in the case of triple collisions of photon/electron/ lattice ions.

\section{Practical Aspects}

The optical properties of gold are not by themselves sufficiently exceptional to justify its choice to the exclusion of other metals, e.g. for the reflection of IR rays. It must be admitted that transition metals such as nickel, palladium and platinum tend to absorb appreciable amounts of radiation in the near IR range. On the other hand, some high electrical conductivity metals like silver, aluminium or copper reflect IR and the red portion of the visible spectrum almost as completely as gold. This means that they could be used as substitutes. However, silver tarnishes and forms silver sulphide while aluminium and copper oxidise in air. Any chemical reaction on the surface changes fundamentally the optical properties. Reflecting surfaces must remain 


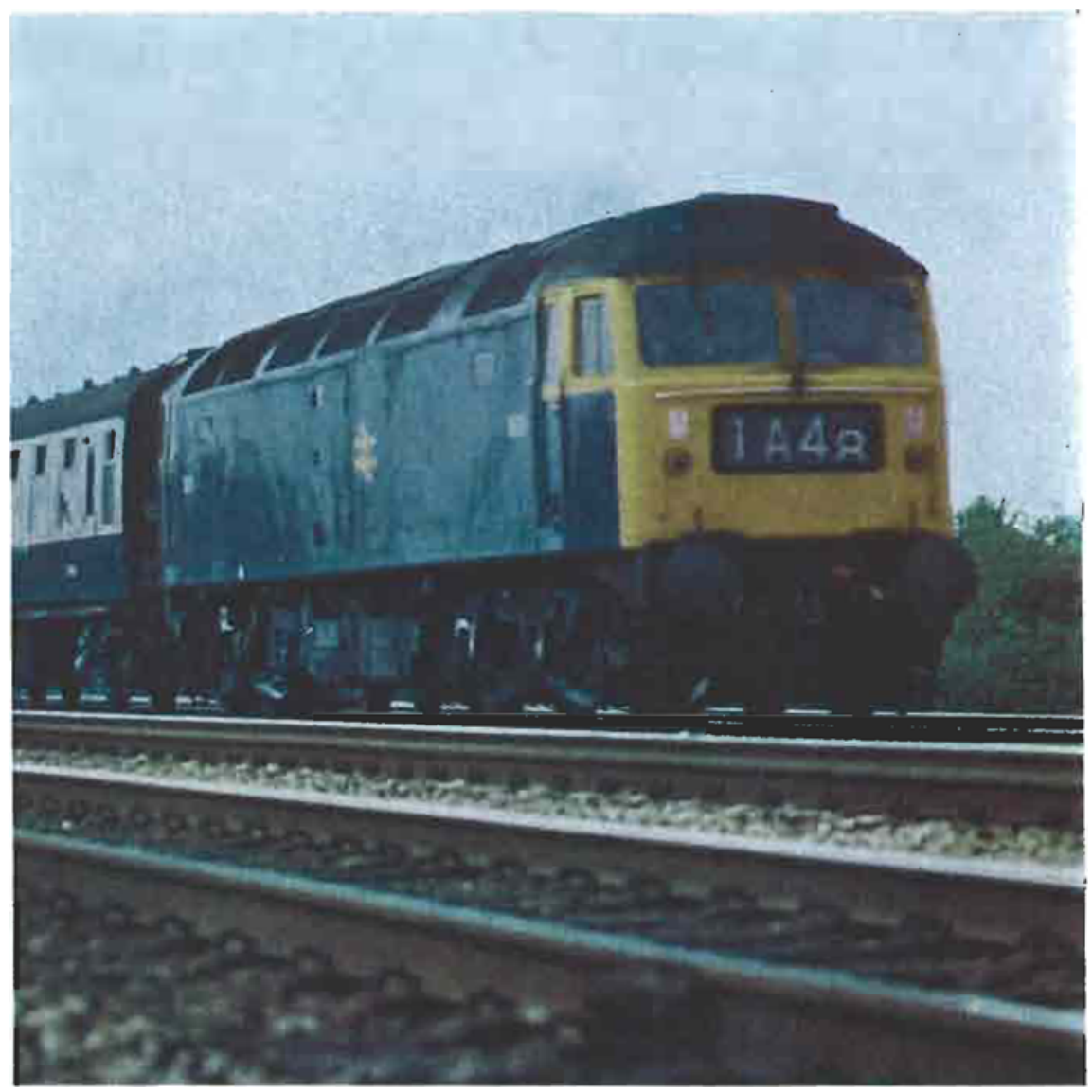

A thin gold film that is virtually transparent but capable of carrying an electric current is the basis of heated windsereens for aircraft, ships, hovereraft, and locomotives. Gold film leated windscreens are being supplied by Triplex Safety Glass to British Railways and to a number of other railway systems to provide clear vision combined with de-icing and de-misting facilities

optically unchanged over long periods in store or in use and gold is, therefore, the only alternative.

The use of gold for applications listed earlier in this paper is, therefore, due equally to its special optical properties and to its exceptionally high chemical resistance in any type of surroundings.

The high basic cost of gold has been kept within acceptable limits for all these applications. Remembering the extremely low penetration depth of light waves of all frequencies into the gold lattice, thin gold films react in the same way as bulk metal. The characteristic optical properties of gold are displayed by films only a few tenths of a micron thick. Thicknesses in this region are easy to produce by conventional methods. Metal backings are electroplated; insulating surfaces receive a conducting interlayer, e.g. by the processes used for ABS plastics. Other materials and components are coated by high vacuum or by ultra-high vacuum deposition. Another common practice is coating by sputtering. Refractory surfaces can be coated by a thin fired film of liquid gold. Materials sensitive to heat have been coated by the Lockspray process whereby a gold solution and a reducing agent are sprayed on by twin jets.
1 M. E. Browning, Galvanotechnik, 1966, 57, 433

2 Dettner/Elze, Handb. Galvanotechnik, 1966, Band II, 988

3 P. F. Dickson and M. C. Jones, N.B.S. Tech. Note 348, 1966

4 C. v. Fragstein and H. Kampermann, Z. Phys., 1963, 173, 39

5 H. Freund, Handbuch der Mikroskopie in der Technik, Frankfurt, 1969, Band III, Part 2, 1

6 H. Kautz, Stahleisen-Sonderbericht 2, Duisseldorf, 1960

7 H. Knosp, Z. Metallkunde, 1969, 60, 526

8 W. Köster and R. Stahl, Ibid, 1967, 58, 768

9 R. Kretzmann, Ann. Physik, 5 Folge, 1940, 37, 303

10 A. v. Krusenstjern, Edelmetallgalvanotechnik, E. Leuze Saulgau, 1970, 278

11 H. Mayer, Physik dimner Schichten, Stuttgart, 1950

12 P. O. Nilsson, Phys. Kondens. Mater, 1970, 11, 1

13 M. Otter, Z. Phys., 1961, 161, 163, 539

14 W. Pepperhoff, Temperaturstrahlung, Darmstadt, 1956

\section{References}

15 G. Pfestorf, Ann. Physik, 4 Folge, 1926, 81, 906

16 R. Philip, Compt. Rend., 1958, 247, 1104

17 S. Robin, Ibid., 1953, 236, 674

18 G. Schröder, Feinwerktechnik, 1968, 72, 329, 583

19 L. G. Schulz, 7. Opt. Soc. Am., 1954, 44, 357, 362

20 R. Schulze, Ann. Physik, 5 Folge, 1937, 34, 24

$21 \mathrm{H}$. Stabe, Feinwerktechnik, 1953, 57, 199

22 R. Stahi, H. J. Spranger and H. P. Aubauer, Z. Metallkunde, 1969, 60, 934

23 G. L. Tugwell, Metal Prog., 1965, 88, 73; R. C. Langley, Gold Bull., 1971, 4, 62

24 E. M. Wise, Gold: Recovery, Properties and Applications, London, 1964

25 A. G. Worthing, Phys. Rev., 1926, 28, 174

26 Prospektangaben der Fa. DETAG A.G., Witten/Ruhr

27 Prospektangaben der Fa. Dr. Heidenhain, Traunreut

28 W. C. Heraeus, DGM 6909417

29 Engelhard Ind, German Offen. 1,540,740 